important of engineering alloys, and it was soon supplemented by the equally fruitful discovery by Petch and Hall (the author of the book under review) of the relation. ship between yield stress and grain size. The study of yielding built up to a peak in the early sixties, since when the impetus has gradually departed, leaving, however, a very substantial body of knowledge and insight. It is this material which Hall has very ably marshalled in his book.

The text begins by analysing the features common to all forms of yielding, including its propagation in the form of Lüders bands and also "false yield-points". He goes on to a very thorough disquisition on yielding, strain-ageing, quench-ageing and blue-brittleness (dynamic strain-ageing by an old-fashioned name) in iron alloys. This chapter is the core of the book. It is surprising to find that, in the author's view, the theoretical details of the strain-ageing process and the associated yield behaviour are still not entirely clear, but his conscientious literature survey certainly confirms his conclusion. This is one of the few fields of modern metallurgy where the electron microscope has failed to contribute anything of value. Later chapters deal with a range of other metals and also with the special features of hydrogen as solute. Short sections also deal with ordered alloys, whiskers, ionic crystals and semiconducting materials.

All in all, this is a very professional, thorough and notably critical survey of its field, and, indeed, its eomprehensive coverage of the literature alone would guarantee it a place on the shelves of metallurgical libraries.

R. W. CAHN

\section{CONSTRUCTION KITS}

\section{Orbit Molecular Building Set}

(Designed and Manufactured by RJM Exports Ltd. Distributed by Wiley: Chichoster (universities and tochnical colleges); Macmillan: London (schools), July 1970.) $21(s)$ (demonstration kit); $56 s$ (student kit). (Sample kit free on request.)

\section{Elements of Protein Synthesis}

An Instructional Model. By Thomas Peter Bennett. \$3. A Guide to the Instructional Model. Pp. 40. $\$ 0.75$. (W. H. Freeman: San Francisco and Folkestone, 1969.)

Is an age when model building is all the craze for molecular biologists, it is important that students should be able to indulge in this art if they are to appreciate its usefulness and limitations. The Orbit Molecular Building Set is one of the most promising models on the market, with the advantage that it is easy to use and the student set is cheap enough for the student pocket. The atorns are precast spheres with arms at the correct bond angles and they aro joined together by short lengths of plastic tubes rather like drinking straws. By cutting the straw's provided into suitable lengths, any convenient scale can be chosen, from about 2 crn por angstrom upward.

The kit is best for constructing rather small assemblies such as one base pair of a DNA double helix or a short oligopeptide. It is more difficult to build complicated tertiary structures; it is not easy, for example, to construct a DNA double helix of five-ten base pairs, without knowing in some detail just what positions the atoms take up about bonds of free rotation. One difficulty is that the atoms do not rotate very frecly. A space filling model would perhaps give a better idea of the real configuration of molecules, but in lieu of the ready availability of such a kit, the Orbit kit can be recommended to students who will undoubtedly enjoy piecing macromolecules together.

The Elements of Protein Synthesis model consists of a two-dimensional cardboard cut-out kit, with parts to represent the ribosome, mRNA, and aminoacyl-tRNA.
In short, it is a sort of do-it-yourself kit for producing a moving cartoon from the types of illustration favoured in molecular biology articles in the Scientific American. To suppose that this will enhance a student's understanding of how the components of protein synthesis interact is optimistic. I advise students to save their money and buy a well illustrated text. BEN.JAmin LEwIN

\section{ONE SIDED MICROCIRCULATION}

\section{Microcirculation, Perfusion and Transplantation of Organs}

Edited by T. I. Malinin, B. S. Linn, A. B. Callahan and W. D. Warren. (Proceedings of a Conference hold in Miami, Florida, October 30, 1969.) Pp. xvi+423. (Academic: New York and London, June 1970.) \$12.50.

ThIs volume is a collection of communications delivered at a conferenco sponsored by US Naval Research and the University of Miami. The chief aim of the conference was to bring together the views of clinicians and physiologists on the complexities of organ transplants, rejection, storage and perfusion and their relation to the microcirculation.

There are three principal sections to this volume-the microcirculation under normal conditions, the pathology and pathophysiology of the microcirculation, and the perfusion of organs. In the first section, the papers arc of a general nature and no effort is made to relate them to transplantation problems. And yet this was what the conference was all about. The speakers in all three sections should have met before the conference and worked out together some aspects of the theory and practice of organ transplantation because without a discussion at the end of each section the communications scem isolated.

A review of the ultrastructure of freeze-cleared capillaries is interesting but of limited interest if no effort is made to relate detectable damage to functional impairment. After all, electron microscopy has given us very little insight into glomerular protein leakage in most forms of the nephrotic syndrome. Considering that arteriographic and blood flow studies, indicating the principal features of rejection of organ transplants, were published in Europe more than a decade ago, it is surprising that this aspect of the microcirculation was not mentioned.

Only American researchers attended this conference and it is exactly under such circumstances that a splendid isolationism develops. One or two references are made to European work which is all the more absurd because much of the early work on the microcirculatory problem of transplanted organs appeared first in European journals. Of course, most authors made it clear that they would not be presenting an extensive list of references, and so instead of presenting confirmatory evidence of previously published data one is loft with what could seem to be an original statement requiring confirmation itself.

What is so refreshing about the attitude taken by some American authors is that there is always somebody there to debunk it. F. Gollan, in his introductory remarks to "In vivo Perfusion of Hearts", felt constrained to state "I do not suggest a complete or even comprehensive bibliography in every paper in traditional physiological ficlds, but I do suggest, however, that results which were obtained by other investigators, no matter how long ago and in what country, should be examined and relied upon before subsequent experiments are proposed in the same field of investigation. The tendeney in many recent: publications to cite primarily only contemporary authors appears to lead to much unnecessary work and reduplication of effort". W. J. DEMPSTER 